\title{
Wage differentials of males and females in same-sex and different-sex couples in Canada, 2006-2010
}

\author{
Richard E. Mueller ${ }^{1}$
}

\begin{abstract}
This paper utilizes five cycles of the General Social Survey in consecutive years from 2006 through 2010 to address the issue of differential wages amongst members of same-sex couples compared to their counterparts in different-sex couples. We find that men in gay couples have wages that are statistically indistinguishable from those of males in heterosexual relationships. By contrast, a sizeable and statistically significant earnings premium exists for lesbians in same-sex couples.
\end{abstract}

Keywords: General Social Survey, differential wages, same-sex couples, earnings premium.

\section{Résumé}

Cet article fait appel à cinq cycles de l'Enquête sociale générale, soit de 2006 à 2010, dans le but d'aborder la question des différences de salaires chez les membres des couples de même sexe par rapport à leurs homologues des couples hétérosexuels. Nous avons constaté que le salaire des hommes des couples homosexuels ne se distingue pas sur le plan statistique des hommes des couples hétérosexuels. Par ailleurs, il y avait une différence appréciable et considérable sur le plan statistique du salaire des femmes des couples homosexuels et celles des couples hétérosexuels.

Mots-clés : enquête sociale générale, différences des salaires, couples de même sexe, prime salariale.

\section{Introduction}

Same-sex couples in Canada have had the same right to marry as their different-sex counterpart since July 2005. Although legally same-sex couples cannot be discriminated against in their choice of a marriage partner, we have little evidence to suggest that discrimination does not exist in other aspects of their lives. In particular, does this legal equality in marriage extend to the workplace in Canada? Do members of same-sex couples have labour market earnings that are comparable to those of members of different-sex couples? Can differences be explained by observable differences between those in same-sex and different sex-partnerships? If they cannot, then discrimination against members of same-sex couples may exist.

In comparison to the volume of work that has been conducted on gender, immigrant, and racial differences in wages, there has been relatively little research using reliable data performed on the labour market experiences of gays, lesbians, and bisexuals (GLB, to use the common acronym) anywhere in the world. In Canada, only four studies have been completed to date (Mueller 2007; Carpenter 2008;

1. Prentice Research Affiliate, Prentice Institute for Global Population \& Economy, Department of Economics, University of Lethbridge, 4401 University Drive West, Lethbridge AB Canada T1K 3M4.

Email: richard.mueller@uleth.ca. 
LaFrance et al. 2009; Harris 2012). Still, there is increasing interest in Canada, especially as the rights of gays and lesbians to enter into marriages equal to the rights of heterosexual couples have recently been made the law of the land. Part of the reason for the lack of information in this area is undoubtedly the paucity of appropriate data on the subject. Also, arguably, the GLB rights movement in most countries is relatively new and still in its infancy compared to the women's and minority rights movements of the post-World War II period. These latter two movements undoubtedly spawned the collection of appropriate data that allowed competent earnings differential studies to be completed.

The purpose of this paper is to try to corroborate and complement the existing Canadian evidence on GLB earnings differentials (i.e., Mueller 2007; Carpenter 2008; LaFrance et al. 2009; Harris 2012). We do this by using five cycles of the General Social Survey between 2006 and 2010 - compared to the Canadian Community Health Survey (CCHS), which is used by the latter three of the four Canadian papers listed above. The GSS complements the CCHS, since it is exclusively done via telephone interview and thus may elicit responses that are more accurate than the CCHS, especially considering the sensitive nature of questions about sexual behaviour. The other paper (Mueller 2007) also uses the GSS, but only uses one cycle from 2001, which suffers from a small number of gay and lesbian same-sex partners in the data. Furthermore, these individuals are not identified directly (rather, they are identified by a variable derived from whether an individual has a partner and the sex of that partner), and none are self-identified as married (since the 2001 data predate the legalization of same-sex marriage in Canada). Our results show that gay men do not earn significantly less than their observationally equivalent heterosexual counterparts, while lesbian females earn significantly more.

In this paper, the next section discusses the literature on the earnings differentials of GLB vis-à-vis the heterosexual majority in the United States, Canada, and other countries. The third section discusses the data and methodology utilized, as well as the limitations of both. The multivariate estimation results are presented in the fourth section, followed by the conclusions in the fifth and final section.

\section{Literature review}

A number of recent studies have been conducted on earnings or wage differentials of homosexuals and/or bisexuals throughout the world; this phenomenon is due, at least in part, to the increasing availability of reliable data on same-sex behaviour. The pioneering work in this area (Badgett 1995), as well as many subsequent studies, was done for the United States and used the General Social Survey (GSS) in that country (Berg and Lien 2002; Black et al. 2003; Blandford 2003; Zavodny 2007). ${ }^{2}$ All of these studies define same-sex behaviour in one or more of the following ways: any same-sex behaviour since age 18, same-sex sexual behaviour in the past five years, any same-sex sexual behaviour in the past year, or more same-sex than different-sex partners over the appropriate timeframe. In other words, sexual orientation is behaviour-based and depends on the relative number of same- and different-sex partners over a specific timeframe. Although each of these studies uses slightly different

2. Additional international evidence is supplied from the Netherlands by Plug and Berkhout (2004). They discover that self-identified gay males earn about three per cent less - and lesbian females about three per cent more - than observationally equivalent recent graduates of tertiary education. For the UK, Frank (2006) finds no evidence of any earnings penalty for self-identified GLB, but his study uses only data from UK universities and he does argue that GLB face a glass ceiling when it comes to career advancement. Another study for the UK (Arabsheibani et al. 2005) finds that male same-sex partners are at a five per cent earnings disadvantage compared to their different-sex partnered counterparts, whereas same-sex females earn about eight per cent more. Heineck (2009) pools data from the US, Australia, Ireland, Poland, and Bulgaria, and finds a wage penalty for gay men but no penalty for lesbians or bisexual men or women. 
Mueller: Wage differentials of males and females in same-sex and different-sex couples in Canada

versions of the GSS, as well as various methodologies, all arrive at the same basic conclusion: there is a double-digit earnings penalty for gay men and a double-digit earnings premium for lesbian women compared to their observationally equivalent heterosexual counterparts. Carpenter (2007) confirms these results using the Third National Health and Nutrition Examination Survey (NHANES III). He also finds that those who are the most behaviourally gay (as measured by the proportion of same-sex to opposite-sex partners) have the largest income penalties.

Other research for the United States has relied on the 1990 US Census. While the GSS definition of gays and lesbians (and sometimes bisexuals) is based on sexual behaviour, the census permits researchers to derive a same-sex partnership variable based on the cohabitation status of two partners and their sexes. Allegretto and Arthur (2001) argue that this self-reporting of lifestyle (i.e., cohabitating with a member of the same sex) is a strong point of their study - rather than defining gay men as those who have had homosexual experiences - since these experiences could have been experimental and not necessarily indicative of sexual orientation. This is especially true for younger adults, who are more likely to have some same-sex experiences before settling into a different-sex relationship. Klawitter and Flatt (1998) and Clain and Leppel (2001) also use this data and define homosexuals in the same way. These studies all find that men in same-sex partnerships earn less than males in different-sex unmarried partnerships, and less still compared to married males. The latter two studies also find a premium for lesbians in same-sex partnerships relative to females with different-sex partners. Carpenter (2004) also studies same-sex unmarried partners. He uses the same definition as that used by researchers utilizing the census, but pooled data between 1996 and 2000 from the Centers for Disease Control's Behavioral Risk Factor Surveillance System. Regardless, he finds a penalty for both male and female same-sex cohabitating couples compared to those living in a different-sex relationship, but a significantly larger penalty for both gays and lesbians relative to those in a marriage.

More recently, Antecol et al. (2007) use the 2000 US Census and find that coupled lesbian women earn more than married or cohabiting heterosexual females, while coupled gay men earn less than their married heterosexual counterparts, but more than cohabitating heterosexual males. Jepson (2007) also uses the 2000 Census and comes to similar conclusions, while limiting her analysis to cohabiting lesbians relative to married and cohabiting heterosexual females.

Generally, the results from the GSS (as well as other datasets such as the NHANES) suggest that the more behaviourally gay an individual is - based on a larger proportion of same-sex to oppositesex partners — the larger the income penalty. As Badgett (1995: 731) points out: "A variable measuring the extent of workplace disclosure of gay behavior or identity would be more appropriate to include in the wage equation, since disclosure is necessary for direct discrimination to occur. Unfortunately, this information is not available." More specifically, this information was not available at the time of Badgett's study. Carpenter (2005) tries to overcome this identification problem using data from the California Health Interview Survey, in which GLB self-identify. Doing so, he finds no statistical or economically significant gay or lesbian effect on earnings compared to heterosexuals, although he does find some evidence of a penalty amongst bisexuals as well as a marriage effect. Whether this is due to a California regional effect or some other factor is not clear. Most recently, Montag (2011) utilizes the 2008 American Community Survey; arguing that it provides a fuller sample of same-sex couples than earlier waves of the survey or the US census, he finds that there is no statistical difference between married gays and lesbians and gays and lesbians who are partnered but not married.

Similarly, Carpenter (2008) also uses the self-identification method in the first published study conducted on Canadian GLB. He uses the 2003 and 2005 Canadian Community Health Survey (CCHS) which explicitly asks individuals whether they consider themselves to be heterosexual, homosexual, or 
bisexual. He argues that this may be better than other ways of identifying sexual orientation, since selfreporting in the survey is likely closer to workplace disclosure of the same. In other words, those who classified themselves as GLB in the survey are also likely to be open about their sexual orientation to employers and colleagues. He finds that the personal incomes of gay men are about 12 per cent less than non-gay men, and that lesbians have an advantage of about 15 per cent. Limiting the sample to only "partnered" individuals, he finds differentials of -21.0 per cent for partnered gay males compared to partnered heterosexual males, and a premium of 35.9 per cent for partnered lesbians. Also using the CCHS (2003, 2004, and 2007-08), Lafrance et al. (2009) find that among those working 30 or more hours per week, partnered gay men earn about 20 per cent less than married heterosexual males and some 7 per cent less than common-law heterosexual males outside of Quebec. By contrast, partnered lesbians earn more-about 10 per cent more than married heterosexual females and seven per cent more than heterosexual common-law females outside of Quebec. ${ }^{3}$ Most recently, Harris (2012), using seven cycles of the CCHS between 2003 and 2009, finds that partnered gay men earn 15 per cent less than men in opposite-sex partnerships, but that lesbian females earn the same as partnered female heterosexuals. Harris attributes this difference to lower work stress among partnered gays compared to their heterosexual partnered counterparts. Using the GSS from 2001, Mueller (2007) finds that partnered gay males have incomes about 21 per cent lower than partnered straight males, while partnered lesbians have incomes that are statistically indistinguishable from their straight counterparts.

In sum, the results of this sparse literature on same-sex wage differentials are consistent in the direction of earnings differential, but the magnitude can differ depending on the definition of homosexuality that is utilized. Generally, the literature suggests that those in same-sex gay (lesbian) relationships earn less (more) than those in relationships that contain two individuals of the opposite sex, and further, that the marriage effect tends to be significant. Furthermore, studies that use data in which individuals self-identify show a lower GLB effect than any of the studies that use the behaviour definition based on the number and sex of sexual partners.

\section{Data and methodology}

As mentioned above, there have been differences in the literature regarding how to define homosexuals, largely owing to the differences in definitions contained in the datasets utilized. Badgett (1995), as well as many who have followed, uses the sexual behaviour of individuals, rather than self-reporting of sexual orientation, to identify gays and lesbians. This often produces a variance of estimates, depending on whether individuals are classified based on the sex of the majority of their sexual partners, any sexual activity with a same-sex partner, the timeframe involved in reporting (e.g., one year versus lifetime), etc. Furthermore, the sexual behaviour of individuals changes over time; their sexual orientation does not (Black et al. 2003). For example, young people are more likely to flirt with homosexuality and bisexuality before settling into a permanent heterosexual orientation. Obviously, the corresponding estimates of wage or earnings premia or penalties also tend to vary depending on the definition and the related concept of "openness" of an individual's homosexuality or bisexuality (Blandford 2003; Carpenter 2007).

In Canada there are only three datasets capable of comparing the labour market experiences of GLB with those of their heterosexual counterparts: the Census, the Canadian Community Health Survey (CCHS), and the General Social Survey (GSS). Both the Census and the GSS use two individuals of the same sex in a common-law or married relationship to define gays and lesbians. Of course,

3. These are calculated from Tables 4 and 5 in Lafrance et al. (2009). 
Mueller: Wage differentials of males and females in same-sex and different-sex couples in Canada

bisexuals cannot be identified in this way, nor can gays and lesbians outside of a partnership, or those who may be GLB and also in a common-law or married heterosexual relationship. The CCHS asks individuals if they consider themselves to be homosexual, bisexual, or heterosexual. The potential identification of GLB is therefore much greater than in the Census or the GSS, but until 2005 the CCHS lacked information on such individuals' common-law status, unless they were married (a rare event). Another important difference is that the GSS is exclusively a telephone survey, compared to a mixture of telephone and face-to-face interviews conducted for the CCHS, and the household identification which is collected on census forms. ${ }^{4}$ Thus, the GSS offers respondents a greater degree of confidentiality than either the census or the CCHS. This may be important, given the potentially sensitive nature about revealing one's sexual orientation.

The data we utilize are from the public use microdata files of the 2006 through 2010 GSS (Cycles 20 through 24). This survey asks explicitly about the marital or common-law status of the household reference person, where the options are no partner, a married partner, a common-law partner or a same-sex partner. ${ }^{5}$ In addition, combining the same-sex partner variable with the marital status variable further allows us to ascertain those in same-sex partnership who are married versus those who are common-law. The surveys contain a total combined unweighted sample of 102,225 individuals from all ten provinces but not the three territories, of whom 355 are in same-sex partnerships (144 gay males and 211 lesbian females). In the weighted original sample, these 355 individuals represent about 0.39 per cent of the relevant population 15 years of age and older, with a slightly lower proportion of males in same-sex partnerships than females (0.38 versus 0.41$).{ }^{6}$ Partnered gays and lesbians account for 0.63 per cent of all married and common-law relationships. This proportion, however, is not distributed evenly amongst age groups, with gays and lesbians in the 15-24 and 65+ age groups having a lower proportion of all marriages and common-law relationships. ${ }^{7}$ This could indicate that gays and lesbians in the middle of the age distribution are more comfortable with revealing their true sexual preference or - in the case of the very young-less likely to be in a married or common-law relationship compared to their heterosexual counterparts. Unfortunately, we have no way of identifying the reasons for these differences in the data.

After the final sample selection, partnered gay men comprise about 0.71 per cent of all partnered men. This figure for gays is comparable to other Canadian datasets. For example, in Carpenter (2008) some 0.77 per cent of partnered men are gay, while in Lafrance et al. (2009) and Harris (2012), the figures are 0.74 and 0.79 per cent, respectively. For partnered females, however, the proportion of lesbians in our sample is somewhat higher-about 0.93 per cent, compared to 0.53 per cent in Carpenter, 0.64 per cent in Lafrance et al. and 0.67 per cent in Harris. ${ }^{8}$ In sum, our data contain about the same proportion of partnered gay males, but many more partnered lesbians. The proportion of

4. According to Harris (2012), about one-half of the CCHS sample comes from physical household interviews, with the other half from random telephone calls.

5. Prior to Cycle 20, it was possible to determine same-sex partnerships, but only by combining variables that asked about partner type (no partner, common law partner, or married partner) and the variable for sex of the partner.

6. The GSS generally surveys those 15 years of age and older. The exception in the data used here is for GSS Cycle 21 (2007), where the universe is those over 45 years of age. The main results presented below are robust to the omission of Cycle 21 from the dataset.

7. Partnered gays and lesbians as a proportion of all marriages and common-law relationships by age group in our data are: ages 15-24 (0.34 per cent), 25-34 (0.65 per cent), 35-44 (0.87 per cent), 45-54 (0.82 per cent), 55-64 (0.49 per cent), and over the age of 65 (0.29 per cent).

8. The figures from Carpenter (2008), Lafrance et al. (2009), and Harris (2012) were derived from the tables of summary statistics contained in each of these three papers. When data cuts were changed to be as consistent as possible with the age cuts in these studies, the results presented below were similar to these original studies. 
same-sex couples is also similar to the figure in the recent Canadian census.. ${ }^{9}$ Finally, previous evidence for the United States (Black et al. 2000; Carpenter 2004) shows that the assumption that an adult cohabitating with another same-sex adult is behaviourally gay or lesbian is likely to be correct. To summarize, the GSS seems to correctly capture a favourable proportion of same-sex couples compared to other data from the US and Canada. Of course, the limitation of these data-as with all surveys that use self-reported sexual orientation status - is that the true population proportion of partnered gays and lesbians could be overestimated or underestimated.

The GSS does not contain a continuous variable for hourly wages; rather it contains a categorical variable for annual personal income (which includes income from all sources). To mitigate potential bias, only those who claimed employment or self-employment income as the main source of income were retained. ${ }^{10}$ The mid-point values of each category for personal income are divided by the annual number of hours worked (i.e., weeks worked multiplied by hours per week) to arrive at the hourly wage variable, and then transformed into a real wage variable by deflating the nominal wage rate in each year by the consumer price index. ${ }^{11}$

Our final sample is obtained by dropping those who were attending school full-time and eliminating those under the age of 20 and over the age of 60 (to concentrate on individuals who are most likely to have a strong attachment to the labour force). Those with missing responses to various questions were also eliminated, as were those with real hourly wages of less than five dollars or more than five hundred dollars. Since only gays and lesbians residing in same-sex partnerships can be observed in the data, we limit the heterosexual sample to include only those in common-law or married partnerships. Individual weights were used for each respondent to account for the weights in the original cycle of the GSS, and then reweighted to account for pooling the data across the five cycles of the GSS.

The final sample size contains 14,021 males, 90 of whom reported to be in a same-sex partnership. The female sample contains 11,498 observations, of which 118 are in same-sex couples. All individuals that meet the above criteria are included in this final sample. ${ }^{12}$ In the weighted sample, some 0.71 per cent of partnered males and 0.93 per cent of partnered females are involved in same-sex relationships.

9. For example, it is relatively straightforward to determine the proportion of same-sex couples in the 2001, 2006, and 2011 census (go to statcan.gc.ca and follow the Census links). In each of these years, Statistics Canada lists the number of same-sex couples among the population 15 years and older. Multiplying this number by two and then dividing by the total population aged 15 years and older yields $0.28,0.35$, and 0.46 per cent of the relevant population as being in same-sex couples in 2001, 2006, and 2011, respectively. These are comparable to the figures in the uncut GSS data. With the exception of the 2007 GSS (which only surveys those 45 years of age and older), the proportion of same-sex couples as a percentage of the population aged $15+$ is 0.25 in 2006, 0.42 in 2008 and 2009, and 0.44 in 2010. The fact that the proportion increases likely reflects the increasing willingness over time of gays and lesbians to self-report their true sexual orientation.

10. The non-response rate to the personal income question (i.e., where the response is either "not stated" or "don't know") is 19.2 per cent on average amongst couples in the raw data over the 5 cycles of the GSS. The rate is not random but rather higher for those in different-sex couples (19.3 per cent) than for those in same-sex couples (11.0 per cent). This rate is negatively related to years of education and positively related to full-time and full-year labour force status. $\chi^{2}$ tests confirm that these differences are statistically different. Furthermore, a logit model with non-response to the income question as the outcome variable yielded significant odds ratios of $0.54,0.91$, and 1.08 on the same-sex partner, years of education, and full-time/full-year variables, respectively.

11. The consumer price index is from CANSIM Table 326-0020. A number of models using real personal income as the dependent variable were also estimated. The results were very similar to those presented below.

12. Starting with 355 observations in the data for those in same-sex partnerships, we arrive at 208 observations by eliminating 147 observations in the following order: those who are 65 years of age or older (28 observations dropped), or less than 20 years of age (1); respondents who claimed no personal income (7); respondents whose main activity in the previous year was not "working at a paid job or business" (79); those 
Mueller: Wage differentials of males and females in same-sex and different-sex couples in Canada

Table 1a: Summary statistics, males, different-sex and same-sex couples.

\begin{tabular}{|c|c|c|c|c|c|c|c|c|c|}
\hline & \multicolumn{4}{|c|}{ Different-sex couple } & \multicolumn{4}{|c|}{ Same-sex couple } & \multirow{2}{*}{$\begin{array}{l}\text { diff. in } \\
\text { means }\end{array}$} \\
\hline & mean & s.e. & $\max$ & $\min$ & mean & s.e. & $\max$ & $\min$ & \\
\hline Real hourly wage & 27.35 & 0.141 & 437.06 & 5.01 & 26.31 & 1.460 & 92.46 & 5.25 & -1.043 \\
\hline Log real hourly wage & 3.19 & 0.004 & 6.08 & 1.61 & 3.15 & 0.054 & 4.53 & 1.66 & -0.042 \\
\hline Years of education & 14.03 & 0.020 & 18 & 6 & 14.92 & 0.220 & 18 & 10 & $0.890 * * *$ \\
\hline Doctorate/masters/some graduate & 0.10 & 0.003 & 1 & 0 & 0.17 & 0.040 & 1 & 0 & $0.073 * *$ \\
\hline Bacherlor's degree & 0.22 & 0.003 & 1 & 0 & 0.34 & 0.050 & 1 & 0 & $0.127 * * *$ \\
\hline Diploma/certificate from community college & 0.16 & 0.003 & 1 & 0 & 0.14 & 0.037 & 1 & 0 & -0.018 \\
\hline Diploma/certificate from trade/technical & 0.16 & 0.003 & 1 & 0 & 0.05 & 0.023 & 1 & 0 & $-0.113 * * *$ \\
\hline Some university & 0.04 & 0.002 & 1 & 0 & 0.05 & 0.024 & 1 & 0 & 0.009 \\
\hline Some community college/CEGEP/nursing & 0.04 & 0.002 & 1 & 0 & 0.03 & 0.018 & 1 & 0 & -0.011 \\
\hline Some trade/technical & 0.04 & 0.002 & 1 & 0 & 0.02 & 0.013 & 1 & 0 & -0.021 \\
\hline High school diploma & 0.13 & 0.003 & 1 & 0 & 0.18 & 0.040 & 1 & 0 & 0.042 \\
\hline Some secondary/high school & 0.09 & 0.002 & 1 & 0 & 0.02 & 0.013 & 1 & 0 & $-0.077 * * *$ \\
\hline Elementary school/no schooling & 0.01 & 0.001 & 1 & 0 & 0.00 & 0.000 & 0 & 0 & -0.011 \\
\hline Years of work experience & 25.43 & 0.089 & 51 & 1 & 21.80 & 0.995 & 41 & 1 & $-3.632 * * *$ \\
\hline Married & 0.80 & 0.003 & 1 & 0 & 0.08 & 0.029 & 1 & 0 & $-0.723 * * *$ \\
\hline Urban & 0.74 & 0.004 & 1 & 0 & 0.89 & 0.033 & 1 & 0 & $0.154 * * *$ \\
\hline Immigrant & 0.21 & 0.003 & 1 & 0 & 0.08 & 0.028 & 1 & 0 & $-0.136^{* * *}$ \\
\hline Weeks worked & 50.27 & 0.052 & 52 & 1 & 51.52 & 0.284 & 52 & 26 & $1.247 * *$ \\
\hline Hours per week & 45.33 & 0.090 & 75 & 1 & 42.96 & 1.114 & 75 & 20 & $-2.370 * *$ \\
\hline Children present & 0.43 & 0.004 & 1 & 0 & 0.04 & 0.021 & 1 & 0 & $-0.394 * * *$ \\
\hline Newfoundland and Labrador & 0.01 & 0.001 & 1 & 0 & 0.00 & 0.007 & 1 & 0 & -0.011 \\
\hline Prince Edward Island & 0.00 & 0.001 & 1 & 0 & 0.00 & 0.004 & 1 & 0 & -0.003 \\
\hline Nova Scotia & 0.03 & 0.001 & 1 & 0 & 0.03 & 0.018 & 1 & 0 & 0.001 \\
\hline New Brunswick & 0.02 & 0.001 & 1 & 0 & 0.00 & 0.000 & 0 & 0 & -0.023 \\
\hline Quebec & 0.24 & 0.004 & 1 & 0 & 0.32 & 0.050 & 1 & 0 & $0.084 *$ \\
\hline Ontario & 0.38 & 0.004 & 1 & 0 & 0.46 & 0.053 & 1 & 0 & 0.075 \\
\hline Manitoba & 0.04 & 0.002 & 1 & 0 & 0.00 & 0.000 & 0 & 0 & $-0.036^{*}$ \\
\hline Saskatchewan & 0.03 & 0.001 & 1 & 0 & 0.01 & 0.011 & 1 & 0 & -0.018 \\
\hline Alberta & 0.11 & 0.003 & 1 & 0 & 0.08 & 0.028 & 1 & 0 & -0.037 \\
\hline British Columbia & 0.13 & 0.003 & 1 & 0 & 0.10 & 0.031 & 1 & 0 & -0.033 \\
\hline Sample size & 13,931 & & & & 90 & & & & \\
\hline
\end{tabular}

Note: One, five, and ten per cent levels of significance are denoted by ***,**, and *, respectively.

Summary statistics are presented in Table 1. The sample is first divided into males and females (Table $1 \mathrm{a}$ and Table 1b, respectively), and then into different-sex and same-sex couples. The final column within each table contains differences in means between the different-sex and same-sex partnered individuals. The first thing that is worthy of note is that males in same-sex relationships have an unadjusted real hourly wage of $0.042 \mathrm{log}$ points (or 4.3 per cent) less than males in different-sex partnerships (the difference is not statistically significant). ${ }^{13}$ They also possess less experience. However, males in same-sex couples have completed on average almost one additional year of education, with 51 per cent having completed at least a bachelor's degree, compared to only about 32 per cent of heterosexual males in the sample. Gay males

whose main source of income was not from paid or self-employment (8); missing variable values (6); and, finally, those respondents whose real hourly wage was less than $\$ 5$ per hour (2) or greater than $\$ 500$ (16).

13. $\log$ points are converted to percentages by using the formula $y=\left(e^{\mathrm{x}}-1\right) \bullet 100$, where $\mathrm{x}$ is the number of $\log$ points and $y$ is the corresponding percentage. In this case, $\left(e^{-0.042}-1\right) \bullet 100=-4.3 \%$. This same methodology is employed throughout the remainder of the paper. 
are more likely to live in urban areas, and less likely to be immigrants or to be married. ${ }^{14}$ They are somewhat more likely to live in Quebec, and somewhat less likely to live in Manitoba, compared to their heterosexual counterparts. In terms of industry and occupation (not reported), the gay males in the sample are more likely to be found in industries such as educational services, professional, scientific and technical services, information, culture and recreation, etc., and less likely to be in construction and manufacturing. They are also more concentrated in occupations such as health, social sciences, and art and culture, but less likely to be involved in trades and transport and occupations related to primary industry.

Table 1b: Summary statistics, females, different-sex and same-sex couples.

\begin{tabular}{|c|c|c|c|c|c|c|c|c|c|}
\hline & \multicolumn{4}{|c|}{ Different-sex couple } & \multicolumn{4}{|c|}{ Same-sex couple } & \multirow{2}{*}{$\begin{array}{l}\text { diff. in } \\
\text { means }\end{array}$} \\
\hline & mean & s.e. & $\max$ & $\min$ & mean & s.e. & $\max$ & $\min$ & \\
\hline Real hourly wage & 23.23 & 0.1724 & 467.53 & 5.02 & 30.02 & 1.726 & 151.29 & 7.87 & $6.784 * * *$ \\
\hline Log real hourly wage & 2.99 & 0.005 & 6.15 & 1.61 & 3.27 & 0.046 & 5.02 & 2.06 & $0.285 * * *$ \\
\hline Years of education & 14.19 & 0.019 & 18 & 6 & 15.35 & 0.183 & 18 & 10 & $1.153 * * *$ \\
\hline Doctorate/masters/some graduate & 0.09 & 0.003 & 1 & 0 & 0.24 & 0.039 & 1 & 0 & $0.152 * *$ \\
\hline Bacherlor's degree & 0.24 & 0.004 & 1 & 0 & 0.33 & 0.043 & 1 & 0 & 0.088 \\
\hline Diploma/certificate from community college & 0.25 & 0.004 & 1 & 0 & 0.18 & 0.036 & 1 & & $-0.065 * * *$ \\
\hline Diploma/certificate from trade/technical & 0.11 & 0.003 & 1 & 0 & 0.02 & 0.014 & 1 & & $-0.081 * *$ \\
\hline Some university & 0.04 & 0.002 & 1 & 0 & 0.09 & 0.026 & 1 & 0 & 0.047 \\
\hline Some community college/CEGEP/nursing & 0.05 & 0.002 & 1 & 0 & 0.04 & 0.018 & 1 & & -0.014 \\
\hline Some trade/technical & 0.02 & 0.001 & 1 & 0 & 0.03 & 0.016 & 1 & 0 & $0.007 * * *$ \\
\hline High school diploma & 0.15 & 0.003 & 1 & 0 & 0.05 & 0.020 & 1 & & -0.097 \\
\hline Some secondary/high school & 0.05 & 0.002 & 1 & 0 & 0.02 & 0.014 & 1 & & -0.031 \\
\hline Elementary school/no schooling & 0.01 & 0.001 & 1 & 0 & 0.00 & 0.000 & 0 & & $-0.005 * * *$ \\
\hline Years of work experience & 24.78 & 0.100 & 51 & 0 & 23.53 & 0.865 & 43 & & -1.251 \\
\hline Married & 0.79 & 0.004 & 1 & 0 & 0.08 & 0.025 & 1 & & $-0.706 * * *$ \\
\hline Urban & 0.74 & 0.004 & 1 & 0 & 0.88 & 0.030 & 1 & 0 & $0.137 * * *$ \\
\hline Immigrant & 0.19 & 0.004 & 1 & 0 & 0.20 & 0.037 & 1 & 0 & 0.007 \\
\hline Weeks worked & 49.90 & 0.063 & 52 & 1 & 49.89 & 0.569 & 52 & 20 & -0.017 \\
\hline Hours per week & 37.97 & 0.095 & 75 & 1 & 41.31 & 1.004 & 75 & 5 & $3.339 * * *$ \\
\hline Children present & 0.36 & 0.004 & 1 & 0 & 0.07 & 0.024 & 1 & & $-0.287 * * *$ \\
\hline Newfoundland and Labrador & 0.02 & 0.001 & 1 & 0 & 0.02 & 0.012 & 1 & 0 & 0.001 \\
\hline Prince Edward Island & 0.00 & 0.001 & 1 & 0 & 0.00 & 0.006 & 1 & 0 & 0.000 \\
\hline Nova Scotia & 0.03 & 0.002 & 1 & 0 & 0.03 & 0.016 & 1 & 0 & 0.003 \\
\hline New Brunswick & 0.02 & 0.001 & 1 & 0 & 0.02 & 0.014 & 1 & 0 & 0.001 \\
\hline Quebec & 0.25 & 0.004 & 1 & 0 & 0.23 & 0.039 & 1 & & -0.021 \\
\hline Ontario & 0.39 & 0.005 & 1 & 0 & 0.50 & 0.046 & 1 & 0 & $0.109 * *$ \\
\hline Manitoba & 0.03 & 0.002 & 1 & 0 & 0.02 & 0.013 & 1 & & -0.013 \\
\hline Saskatchewan & 0.03 & 0.002 & 1 & 0 & 0.02 & 0.012 & 1 & & -0.013 \\
\hline Alberta & 0.10 & 0.003 & 1 & 0 & 0.08 & 0.025 & 1 & & -0.021 \\
\hline British Columbia & 0.12 & 0.003 & 1 & 0 & 0.07 & 0.024 & 1 & & -0.045 \\
\hline Sample size & 11,380 & & & & 118 & & & & \\
\hline
\end{tabular}

Note: One, five, and ten per cent levels of significance are denoted by ***,**, and *, respectively.

For females, those in same-sex partnerships earn hourly wages that are 0.285 log points $(33.0$ per cent) higher than those in different-sex partnerships. This figure is consistent with more education (with 57 per cent having at least a bachelor's degree, compared to 33 per cent of those in different-sex

14. The urban variable is inconsistent throughout the cycles of the GSS. In Cycles 20 and 21, the urban variable is identified only for residents of Ontario, Quebec, and British Columbia. We ran the main model below to include an urban dummy and also limiting the sample to include only those three provinces. In neither case, nor for either gender, did the main results change. 
Mueller: Wage differentials of males and females in same-sex and different-sex couples in Canada

couples). Lesbians in same-sex couples are much more likely to reside in Ontario. As with partnered gay males, they are more concentrated in urban areas and less likely to be married. In terms of industry, lesbians are more likely to be found in construction, professional, scientific and technical services, and educational services, but less likely to be employed in health care and social assistance. There are no statistically significant differences in occupations between partnered lesbians and partnered heterosexuals.

Thus far, the data show several reasons why gays and lesbians may have different real wage outcomes compared to heterosexuals. The next section of the paper should disentangle these influences.

\section{Multivariate results}

Ordinary least squares (OLS) is the statistical technique most often used in the existing literature on same-sex earnings differentials. We too will use OLS in order to better compare our results with those contained in this body of work. ${ }^{15}$ We also add a correction for robust standard errors throughout the remainder of the paper.

The dependent variable throughout is the natural logarithm of the real hourly wage, to which we add blocks of explanatory variables in a step-wise fashion. Ideally, we would have liked to be able to disaggregate the sample into various groups (e.g., married versus same-sex cohabitating common-law partners) and perform tests to see if this restriction is valid. Unfortunately, sample size does not allow this. Still, the results obtained by Allegretto and Arthur (2001) using both aggregated and disaggregated samples are similar enough to justify using this approach.

Table 2 contains the multivariate results of various specifications of the model. The upper panel contains the results for males, and the lower panel the results for females. The first column in each panel simply reflects the unadjusted real hourly wage differential, without any controls, and reflects the differences shown in Table 1 . The model is gradually built up to include more covariates as we move from left to right. The coefficients normally used in these types of analyses all have the correct signs and reasonable values. For example, the rate of return to a year of schooling is about 0.068 $\log$ points (7.0 per cent) for males and $0.110 \log$ points (11.6 per cent) for women (column 2$)$ and decreases to about $0.049 \log$ points $(5.0$ per cent) for males and $0.080 \log$ points $(8.3$ per cent) for females once all controls are added (column 4). Similarly, the returns to experience increase at a decreasing rate for both males and females; there exists a clear marriage premium for males (but not for women) in the fully loaded model. Immigrants of either gender tend to earn significantly less than their Canadian-born counterparts. These results are well established in the literature.

In column 2, the penalty for gay males increases, indicating that gay males have lower incomes when we account for their higher levels of education and also their fewer years of experience on aver-

15. We also ran a number of other models (not reported here) using real personal income as the outcome variable, as well as a variety of different specifications. Interval and median regressions were also used, because the income variable is reported in intervals in the GSS, and income is not normally distributed. In all cases, the estimates were robust to estimation technique and different model specification. We also attempted to find evidence for the hypothesis that being more openly gay is related to lower earnings. To do this we compared gays and lesbians who were married to those who were not; the assumption being that married gays and lesbians are more likely to be open about their sexual orientation than those who are common-law. Married gays and lesbians did not earn less. Similarly, we hypothesized that gays and lesbians may not suffer from wage discrimination if they are involved in self-employment rather than engaged in paid employment. Again, there was no statistical support for this hypothesis. The small numbers of gays and lesbians who are married and/or involved in self-employment likely result in these large standard errors and thus the lack of statistical significance. Still, this provides an interesting avenue for further research once more data become available. 
Table 2: Estimates of OLS Log real hourly wage equations, males and females.

\begin{tabular}{|c|c|c|c|c|c|c|c|c|}
\hline \multirow[b]{2}{*}{ Males $(n=14,021)$} & \multicolumn{2}{|c|}{ (1) } & \multicolumn{2}{|c|}{$(2)$} & \multicolumn{2}{|c|}{ (3) } & \multicolumn{2}{|c|}{ (4) } \\
\hline & & & & & & & & \\
\hline Gay & -0.042 & 0.062 & -0.078 & 0.057 & -0.046 & 0.055 & -0.060 & 0.055 \\
\hline Years of education & & & 0.068 & $0.002 * * *$ & 0.049 & $0.003 * * *$ & 0.049 & $0.003 * * *$ \\
\hline Years of work experience & & & 0.022 & $0.002 * * *$ & 0.019 & $0.002 * * *$ & 0.017 & $0.002 * * *$ \\
\hline Experience $^{2} / 1000$ & & & -0.293 & $0.041 * * *$ & -0.228 & $0.039 * * *$ & -0.190 & $0.040 * * *$ \\
\hline Married & & & & & 0.065 & $0.012 * * *$ & 0.038 & $0.012 * * *$ \\
\hline Immigrant & & & & & -0.110 & $0.013 * * *$ & -0.130 & $0.013 * * *$ \\
\hline Constant & 3.188 & $0.005 * * *$ & 1.892 & $0.040 * * *$ & 2.014 & $0.045 * * *$ & 2.059 & $0.045^{* * *}$ \\
\hline Occupation/industry controls & No & & No & & Yes & & Yes & \\
\hline Province controls & No & & No & & No & & Yes & \\
\hline Children present & No & & No & & No & & Yes & \\
\hline Year controls & No & & No & & No & & Yes & \\
\hline $\mathrm{R}^{2}$ & 0.0001 & & 0.1157 & & 0.2059 & & 0.2240 & \\
\hline \multicolumn{9}{|l|}{ Females $(\mathrm{n}=11,498)$} \\
\hline Lesbian & 0.285 & $0.053 * * *$ & 0.163 & $0.050 * * *$ & 0.169 & $0.048 * * *$ & 0.163 & $0.047 * * *$ \\
\hline Years of education & & & 0.110 & $0.003 * * *$ & 0.081 & $0.003 * * *$ & 0.080 & $0.003 * * *$ \\
\hline Years of work experience & & & 0.015 & $0.002 * * *$ & 0.012 & $0.002 * * *$ & 0.011 & $0.002 * * *$ \\
\hline Experience $^{2} / 1000$ & & & -0.165 & $0.045^{* * *}$ & -0.120 & $0.043 * * *$ & -0.081 & $0.045^{* * *}$ \\
\hline Married & & & & & 0.026 & $0.013 * *$ & 0.009 & 0.014 \\
\hline Immigrant & & & & & -0.072 & $0.014 * * *$ & -0.099 & $0.014 * * *$ \\
\hline Constant & 2.986 & $0.006^{* * *}$ & 1.165 & $0.050 * * *$ & 1.427 & $0.053 * * *$ & 1.493 & $0.054 * * *$ \\
\hline Occupation/industry controls & No & & No & & Yes & & Yes & \\
\hline Province controls & No & & No & & No & & Yes & \\
\hline Children present & No & & No & & No & & Yes & \\
\hline Year controls & No & & No & & No & & Yes & \\
\hline $\mathrm{R}^{2}$ & 0.0026 & & 0.1625 & & 0.2624 & & 0.2751 & \\
\hline
\end{tabular}

Notes: Standard errors are italicized. One, five, and ten per cent levels of significance are denoted by $* * *, * *$, and *, respectively. Full regression results are available upon request.

age. For lesbians, accounting for more education (but also less experience) reduces the coefficient on the lesbian indicator variable. Adding in a marriage indicator and other variables (column 3) reduces the coefficient on gay but not on lesbian, reflecting the fact that there is relatively large marriage premium for males but not for females. The results in column 4 (the fully loaded model) show that the coefficients on gay and lesbian remain relatively consistent: for gay males there is no statistical wage difference, while for lesbians the premium is $0.163 \log$ points (17.7 per cent) and highly significant.

Allegretto and Arthur (2001) find that men in same-sex cohabiting relationships earn less compared to men in different-sex-relationships, and less still compared to married men. Our results confirm this. They say that the estimates of -2.4 and -15.6 per cent form the upper and lower bounds of the wage penalty for males. Our imprecise estimates fall within this range. Similarly, in other work which addresses same-sex couples, the earnings penalty also tends to be similar to our estimates (Arabsheibani et al. 2005; Carpenter 2004; Clain and Leppel 2003; Klawitter and Flatt 1998).

While comparisons to earlier Canadian studies are tenuous, owing to different datasets (and varying survey questions therein), different time frames, and different comparator groups, as well as possible biases in the data, taken together our results suggest that both gay and lesbian incomes are increasing relative to those in straight partnerships. Mueller (2007) used the 2001 GSS and found that partnered gay males had a significant earnings penalty of about 21 per cent in the fully loaded model, but there was no statistical wage differential among partnered lesbians. In both cases, however, the numbers of gays and lesbians were small, and identification was obtained by merging two variables (sex of partner and common-law status). The more recent evidence for Canada by Carpenter (2008), 
Mueller: Wage differentials of males and females in same-sex and different-sex couples in Canada

Lafrance et al. (2009) and Harris (2012) also generally shows larger penalties for gay males and smaller premiums for lesbians compared to the current results. Taken together, this evidence is (weakly) suggestive of a wage penalty for gay males that may be declining over time.

In sum, we interpret these results to mean that gay men are not at an earning disadvantage. For lesbians, however, there is a large and statistically significant earnings premium in general. Comparing our results with those in the Canadian literature (Carpenter 2008; Harris 2012; LaFrance et al. 2009; Mueller 2007) suggests that the relative earnings position of partnered gays and lesbians may be improving over time, although admittedly this evidence is not very strong.

\section{Conclusions}

We find that men in same-sex couples tend to earn about the same as men in different-sex married and common-law couples. This result is robust across alternative model specifications and data sub-samples. For women, we find a large statistical difference in the earnings of coupled lesbians-about 17.7 per cent. Comparisons with the earlier Canadian literature do suggest that there has been an improvement, although direct comparisons are tenuous owing to different data collection methods, definitions of variables, etc.

While these results could indicate that there is no discrimination in the workplace, especially for gay males, we have no way of being certain about this conclusion. The release of future waves of the GSS, as well as the use of other datasets, will undoubtedly allow researchers to shed more light on this important labour market issue.

\section{Acknowledgment}

The research assistance provided by Bryce van Sluys during the early stages of this project is gratefully acknowledged. Participants at the British Association for Canadian Studies Conference, Durham, United Kingdom, April 11-13, 2007, and seminar participants at the University of Victoria, also provided useful comments on an earlier draft of this paper. Thanks to two anonymous referees whose comments greatly strengthened the current paper.

\section{References}

Allegretto, S.A., and M.M. Arthur. 2001. An empirical analysis of homosexual/heterosexual male earnings differentials: Unmarried and unequal. Industrial and Labour Relations Review 54:631-46.

Antecol, H., A. Jong, and M. Steinberger. 2007. The Sexual Orientation Wage Gap: The Role of Occupational Sorting, Human Capital, and Discrimination. IZA Discussion Paper No. 2945.

Arabsheibani, G. Reza, A. Marin, and J. Wadsworth. 2005. Gay pay in the UK. Economica 72:333-47.

Badgett, M.V. Lee. 1995. The wage effects of sexual orientation discrimination. Industrial and Labour Relations Review 48:726-39.

Berg, N., and D. Lien. 2002. Measuring the effect of sexual orientation on income: Evidence of discrimination? Contemporary Economic Policy 20:394-412.

Black, D., G. Gates, S. Sanders, and L. Taylor. 2000. Demographics of the gay and lesbian population in the United States: Evidence from available systematic data sources. Demography 37:139-54. 
Black, D.A., H.R. Makar, S.G. Sander, and L.J. Taylor. 2003. The earnings effects of sexual orientation. Industrial and Labour Relations Review 56:449-69.

Blandford, J.M. 2003. The nexus of sexual orientation and gender in the determination of earnings. Industrial and Labour Relations Review 56:622-42.

Carpenter, C. 2004. New evidence on gay and lesbian household incomes. Contemporary Economic Policy 21:78-94.

- 2005. Self-reported sexual orientation and earnings: Evidence from California. Industrial and Labour Relations Review 58:258-73.

- 2007. Revisiting the income penalty for behaviorally gay men: Evidence from NHANES III. Labour Economics 14:25-34.

-2008. Sexual orientation, work, and income in Canada. Canadian Journal of Economics 41(4):1239-61.

Clain, S.H., and K. Leppel. 2001. An investigation into sexual orientation discrimination as an explanation for wage differences. Applied Economics 33:37-47.

Frank, J. 2006. Gay glass ceilings. Economica 73:485-508.

Harris, B. 2012. Less Pay for a Less Stressful Day: Sexual Orientation and Household Composition in the Labor Market. Duplicated. Simon Fraser University.

Heineck, G. 2009. Sexual orientation and earnings: Evidence from the ISSP. Applied Economics Letters 16:1351-54.

Jepson, L.K. 2007. Comparing the earnings of cohabiting lesbians, cohabiting heterosexual women, and married women: Evidence from the 2000 Census. Industrial Relations 64:699-727.

Klawitter, M.M., and V. Flatt. 1998. The effect of state and local antidiscrimination policies on earnings for gays and lesbians. Journal of Policy Analysis and Management 17:658-686.

LaFrance, A., C. Warman, and F. Woolley. 2009. Sexual Identity and the Marriage Premium. Queen's Economics Department Working Paper No. 1219.

Montag, J. 2011. Gender Gap Among Gays and Lesbians. Duplicated.

Mueller, R.E. 2007. Straight Pay for the Queer Guy? Earning Differentials of Males and Females in Same-sex Couples in Canada. Duplicated.

Plug, E., and P. Berkhout. 2004. Effects of sexual preferences on earnings in the Netherlands. Journal of Population Economics 17:117-31.

Zavodny, M. 2007. Is there a 'marriage premium' for gay men? Review of Economics of the Household 6:369-89. 